\title{
Rituais de cuidado realizados pelas famílias na preparação para a vivência do parto domiciliar planejado
}

\author{
Rituals of care performed by families in preparing for the experience of planned home birth \\ Rituales de cuidado realizados por las familias en la preparación para la experiencia \\ del parto domiciliario planeado
}

\section{Iara Simoni Silveira Feyer', Marisa Monticelli', Astrid Eggert Boehs', Evanguelia Kotzias Atherino dos Santos'}

' Universidade Federal de Santa Catarina, Centro de Ciências da Saúde, Departamento de Enfermagem, Programa de Pós-Graduação em Enfermagem. Florianópolis - SC, Brasil.

\author{
Submissão: 21-11-2012 Aprovação: 20-11-2013
}

\section{RESUMO}

Esta pesquisa etnográfica objetivou compreender os rituais de cuidado realizados por famílias, durante a preparação para a vivência de parto domiciliar planejado. Participaram 25 famílias, no período de setembro de 2010 a abril de 2011 . As técnicas de coleta de dados foram a observação participante e a entrevista. Mediante processos de apreensão, síntese, teorização e recontextualização, emergiram duas categorias: A casa para nascer e Preparando a chegada do bebê. O parto domiciliar é uma experiência construída no âmbito do casal grávido. A casa é concebida pelas famílias como um local sagrado para a vivência de uma experiência que agregue valores existenciais ao ato fisiológico do nascimento. Compreender esses rituais contribui para o oferecimento de cuidado de enfermagem culturalmente congruente.

Descritores: Parto Domiciliar; Comportamento Ritualístico; Enfermagem Obstétrica; Cultura.

\section{ABSTRACT}

This ethnographic study aimed to understand the rituals of care performed by families, while preparing for the experience of planned home birth. 25 families participated in the period September 2010 to April 2011. The techniques of data collection were participant observation and interview. Through the processes of apprehension, synthesis, theorization and re-contexture, two categories emerged: The house to be born in and Preparing baby's arrival. Homebirth is an experience built within the pregnant couple. The house is considered the sacred place to experience childbirth, aggregating existential values to the physiological act of giving birth. Understanding these rituals contributes to offer a nursing care of quality in order to respect the cultural aspects involved in this assistance.

Key words: Homebirth; Ritualistic Behavior; Obstetric Nursing; Culture.

\section{RESUMEN}

Este estudio etnográfico tuvo como objetivo comprender los rituales de cuidado realizado por las familias, en preparación para la experiencia del parto en casa. 25 familias participaron en el período septiembre 2010 a abril 2011. Las técnicas de recolección de datos fueron la observación participante y la entrevista. Por medio de la recopilación de información, sintetizar, teorizar y recontextualizar, emergieron dos categorías: La casa para el nacimiento y Preparación para la llegada del bebé. El parto en casa es una experiencia construida en la pareja embarazada. La casa está diseñada para las familias como un lugar sagrado para la experiencia de una experiencia existencial que añade valor al proceso fisiológico del nacimiento. La comprensión de estos rituales contribuye a la prestación de cuidados de enfermería culturalmente congruente.

Palabras clave: Parto en Casa; Comportamiento Ritualista; Enfermería Obstétrica; Cultura. 


\section{INTRODUÇÃO}

Atualmente, nos grandes centros urbanos brasileiros, tem havido crescente procura das famílias pelo parto domiciliar planejado $^{(1-3)}$. Cidades como Rio de Janeiro, São Paulo, Brasília, Belo Horizonte e Florianópolis, entre outras, possuem equipes de profissionais de saúde - e, notadamente, de enfermeiras - que prestam esse tipo de assistência(1-2). Essas famílias acreditam que o ambiente doméstico seja o mais adequado para a ocorrência do parto, por compreenderem que, ao contrário da instituição hospitalar, o domicílio propicia atmosfera para vivências com menos intervenções obstétricas e neonatais. Muitas delas escolhem a casa não só como uma maneira de experienciar o fenômeno do nascimento, em si, mas como uma celebração à vida e à nova família ${ }^{(4)}$.

Estudo recente revelou que não é apenas variação de endereço (hospital-casa), e sim, uma mudança que envolve uma série de novos comportamentos, valores e sentimentos relacionados à maneira de dar à luz e nascer ${ }^{(4)}$. As famílias que se aliam a esta proposta são a expressão de um ideário que valoriza a mudança, a vivência do parto como rito de passagem $^{(4-7)}$, e algo que deve ser vivido e experienciado na intimidade do lar. A opção por dar à luz no ambiente da casa está ancorada no "ideário do casal grávido", que pressupõe o igualitarismo entre os papéis feminino e masculino ${ }^{(8)}$.

Portanto, neste contexto, entender os componentes dessa assistência, em sua dimensão simbólica, como a performance de rituais, no âmbito domiciliar de cuidado à saúde da mulher e do recém-nascido, se torna relevante e imprescindível para os profissionais que estão se lançando nesse novo "modelo" assistencial $^{(5)}$. O parto domiciliar incorpora a valorização da ambiência e do protagonismo dos participantes, não apenas enfatizando algo que deveria fazer parte do ciclo de vida das famílias, mas se comprometendo com outras concepções ideológicas igualmente significativas, como a valorização de rituais de cuidado, ou seja, aquelas práticas simbólicas que têm por objetivo ajudar no enfrentamento do "novo" e na redução da incerteza, facilitando a passagem de uma posição ou status da mãe e do recém-nascido, durante o nascimento ${ }^{(6-7)}$.

O cenário dessa nova forma de vivenciar o nascimento aponta para a necessidade de se pesquisar com profundidade os rituais de cuidado que as famílias realizam no parto domiciliar, com a justificativa que tal conhecimento auxiliará os profissionais na compreensão da visão de mundo dessas famílias e, por conseguinte, para contextualizar de modo culturalmente responsável e respeitoso, a rede de símbolos e significados ${ }^{(7)}$ que as mesmas empregam na vivência desta etapa de seu processo de viver. Este propósito se alia também ao intuito de preencher uma lacuna nas publicações deste campo de conhecimento, no Brasil e no exterior, de resultados investigativos que auxiliem os profissionais da área, à aquisição de saberes que contribuam para o exercício e a apropriação da "competência cultural"(9).

Nesta perspectiva, o presente estudo integra um macroprojeto que teve como propósito geral, investigar os rituais de cuidado desenvolvidos pelas famílias no parto domiciliar, tendo por objetivo, neste recorte, compreender os rituais de cuidado realizados por famílias, durante a preparação para a vivência de parto domiciliar planejado. A pesquisa foi desenvolvida sob aporte teórico de autores que estudam o cuidado cultural $^{(9)}$ e o nascimento, sob o ponto de vista antropológico ${ }^{(6-10)}$.

Compreende-se que a identificação das práticas rituais pode ser a chave para que os profissionais de saúde que prestam esse tipo de assistência possam se aprofundar não somente nos aspectos clínicos dessa relação (profissional-cliente), mas também se aproximarem mais da cultura dessas famílias, ajudando a ampliar sua visão de mundo e seu papel social.

\section{METODOLOGIA}

Foi desenvolvido um estudo etnográfico, cujos informantes foram famílias que optaram por vivenciar o parto domiciliar planejado, atendido pelas enfermeiras obstétricas que atuam em Florianópolis-SC. A coleta de dados ocorreu entre os meses de setembro de 2010 a abril de 2011, com 25 famílias, respeitando os princípios de saturação informacional ${ }^{(11)}$.

O estudo etnográfico foi iniciado a partir dos contatos estabelecidos entre a pesquisadora e a equipe de enfermeiras obstétricas que atuam em âmbito domiciliar. O primeiro contato com as famílias se deu através dos encontros mensais, promovido pelas enfermeiras, com a finalidade de esclarecerem as dúvidas dos familiares. A partir daí, a pesquisadora propôs às famílias o acompanhamento do atendimento prestado pelas enfermeiras, no domicílio, sempre que as mesmas realizassem assistência, desde o pré-parto, até o pós-parto, além de incursões no campo, na ausência das enfermeiras.

Em todos os encontros domiciliares, a pesquisadora se colocou no lugar de observadora do comportamento, das falas, dos gestos e das atitudes dos casais e familiares. As técnicas para a coleta de dados foram, por conseguinte, a observação participante e a entrevista. $\mathrm{O}$ registro foi feito em diário de campo e a análise ocorreu em quatro etapas: apreensão, síntese, teorização e recontextualização, procurando responder ao objetivo da pesquisa ${ }^{(12)}$.

A etnografia foi desenvolvida obedecendo aos termos de Resolução 169/96, tendo o projeto sido aprovado no Comitê de Ética da Universidade Federal de Santa Catarina, sob o parecer $n^{\circ} 882 / 10$. As famílias receberam individualmente todas as orientações referentes à pesquisa e assinaram o Termo de Consentimento Livre e Esclarecido. Na apresentação dos resultados foram utilizados nomes fictícios.

\section{RESULTADOS E DISCUSSÃO}

Os procedimentos analíticos resultaram em duas amplas categorias: "A casa para nascer" e "Preparando a chegada do bebê", cada uma das quais englobou outras subcategorias, conforme apresentado a seguir.

\section{A. A casa para nascer}

Observou-se que a decisão pelo parto em casa é fruto da construção de um ideário que se opõe ao modelo hegemônico vigente, resgatando, porém, a ideia de "reclusão" da muIher e da família, para a vivência do parto, de forma mais íntima e localmente significativa ${ }^{(13)}$. Parece tratar-se, portanto, 
de um rito de separação, que guarda semelhança com cerimônias de reclusão da grávida, em cabanas especiais, ou em local peculiar da residência habitual ${ }^{(7)}$, conforme observado pelos estudiosos da antropologia clássica. Essa ressurgência, em nova roupagem, da "casa", como cenário de ritos de passagem, evoca, de alguma maneira, a revitalização do parto e do nascimento como eventos que fazem sentido para a experiência existencial das famílias ${ }^{(4)}$.

\section{A construção do ideário do parto em casa}

A escolha da casa para o nascimento vem ao encontro do que os antropólogos sinalizam sobre os rituais da gravidez e do parto, sendo que esses compreendem práticas que têm o objetivo de facilitar o parto e proteger a mãe e a criança e, frequentemente, também o pai e os demais integrantes da família extensa ${ }^{(7)}$, ao mesmo tempo que esta escolha é necessária para organizar a entrada do novo ser humano no seio da família e também a mulher que se prepara para dar à luz. $\mathrm{O}$ preparo para a chegada do neófito é regimentado por rituais de iniciação e por purificações ambientais que visam garantir a entrada do mesmo na nova condição existencial, mediante limpezas físicas e simbólicas, assim como preparar a mulher para conceber uma nova mãe:

[...] em todos os cantos da sala há pequenos altares, figuras de mestres budistas, incensos para "purificar" o ambiente. A manhã com o casal foi pontuada por conversas sobre o preparo para o dia do parto, com alguns intervalos para que Gil [companheiro] mostrasse os colares de pedras turquesa e coral que está preparando para que Graça [a companheira gestante] use durante a gravidez. Segundo ele, "cada pedra tem um significado especial de conexão com a natureza e as forças que regem a terra" (notas de observação - Graça e Gil).

Como parte da construção desse ideário, praticamente todos os casais grávidos (CGs) foram estimulados, pelas enfermeiras obstétricas, a conhecer a instituição hospitalar para a qual seriam transferidos, caso houvesse intercorrências - uma aceitação parcial do modelo biomédico. Isso faz parte da consolidação de uma responsabilidade compartilhada entre os casais e os profissionais que estão acompanhando a gestação e assistirão o parto, já que o parto domiciliar ainda é uma prática à margem do sistema convencional de saúde:

[...] minha mãe teve parto normal, nunca pensei que comigo fosse diferente. Fui visitar a maternidade e achei o local de uma frieza impressionante (Flávia).

Esse depoimento é significativo para se constatar que o contato com o ambiente hospitalar serviu para que a mulher reafirmasse o propósito de ter seu filho em casa. A decisão pelo parto domiciliar, bem como a sustentação dessa proposta, se dá de forma conjunta, no âmbito do casal.

Estamos fazendo juntos. Ele vai comigo nas consultas com o médico, exames de ultrassom, e estamos nos preparando para vivenciar o parto na nossa casa (Odília).
Raramente, nas interações desses casais, foi pronunciado o pronome "eu"; já a representatividade do "nós" se sobressaia, indicando o casal como a 'pessoa' do discurso. É importante contextualizar que o ideário do CG valora o "novo" e a "mudança", além de pregar o igualitarismo entre os papéis. Ao pressupor uma indiferenciação valorativa entre o masculino e o feminino, o par instiga cada um dos gêneros a ingressar no universo do outro ${ }^{(8)}$.

[...] nós fizemos nosso filho lá no sítio onde morávamos, no meio do mato, com muito amor, o nosso bebê é orgânico (Joana).

[...] essa barriga é nossa, é fruto do nosso amor, eu carrego a barriga e ele cuida, fazendo massagem, passando óleos essenciais (Cecília).

Essas falas revelam que um mecanismo importante para a construção da identidade do CG consiste na demarcação entre o "nós" e os "outros", ou, entre o "aqui" e o "mundo lá fora", repelindo, pelas mais diversas razões, o "outro", e estabelecendo uma solidariedade existencial e ideológica entre os cônjuges ${ }^{(8)}$.

Para o CG, o parto em casa é constituído de preceitos do protagonismo e da autonomia dos participantes, além da ambiência acolhedora relacionada ao modo de vida. Os rituais de preparação na construção desse ideário podem também estar relacionados a uma construção mental de que o parto em casa é o parto ideal, passando a ser referência incontestável quando se trata de "tipos de parto", separando-se das referências anteriores, quase sempre associadas a rotinas desnecessárias e a condutas de exclusão, como o parto vivido passivamente, sem família, sem comida e sujeito às práticas e intervenções 'frias' da técnica e da tecnologia obstétrica. Sendo o parto um rito de passagem, quando vivido em casa, os rituais apresentam maior adesão ao ethos familiar, ao passo que, quando vivido no hospital, apresenta aderência mais aproximada ao modelo dos profissionais ${ }^{(14)}$.

\section{Reafirmações e cisões: a complexidade envolvida na deci- são pelo parto fora do hospital}

No contexto atual, onde o modelo de assistência é predominantemente tecnocrático e baseado em explicações e procedimentos da racionalidade biomédica, alguns casais enfrentam conflitos familiares para reafirmar a decisão pelo parto em casa:

[...] nossa família é contra o parto domiciliar. A família dele [referindo-se ao companheiro] mora aqui na ilha e não temos a menor condição de contar com eles, é muito triste isso (Maria).

[...] meus pais acham o parto domiciliar uma loucura, e não apoiam, por isso decidimos que só estaremos nós em casa (Ana).

Esses depoimentos exemplificam que, dentre os rituais de cuidado de preparação para o parto, os ritos de separação se 
sobressaem e são caracterizados pela conduta simbólica, que significa a ruptura do grupo ou do indivíduo de uma situação anterior dentro da estrutura social ${ }^{(7,15)}$. Para esses casais, cortar vínculos com a família extensa, mesmo que temporariamente, significa um procedimento de separação, com a finalidade de reafirmar que são eles os agentes decisórios e que os fenômenos do parto e nascimento interessam à intimidade do casal e à esfera da vida privada.

No que se refere à relação entre o CG e as famílias de origem, na reafirmação pela escolha do lugar do parto, o preceito de 'quase' desfamiliarização, de certo modo, não implica um rompimento definitivo de relações com a família extensa. O que apregoam é que o casal deva ter uma identidade mais vigorosa do que aquela vinculada com os membros de seus respectivos núcleos familiares de origem ${ }^{(8)}$. Vale ressaltar, contudo, que nem todos os casais passaram por enfrentamentos familiares na reafirmação dessa decisão. Uma parte deles contou com o apoio e o incentivo da família, sem deixar, no entanto, de exercer as suas escolhas com autonomia. Mas esse respaldo, para uma parcela significativa das famílias ocorreu, em grande medida, porque a mãe da grávida ou do futuro pai, já havia experienciado um parto domiciliar.

As famílias que estavam se preparando para o parto em casa, depois de já ter vivido o primeiro parto em âmbito hospitalar, demonstraram, através de seus relatos, a necessidade de buscar uma vivência do parto, que fosse mais íntima, afetuosa e existencialmente significativa para a mulher, e que possibilitasse contato mais direto com o recém-nascido:

O meu primeiro filho foi uma cesárea desnecessária. $O$ pós-parto foi muito sofrido, recebi anestesia geral e só fui conhecer meu filho três horas depois [...] depois que fiquei grávida de novo, queria ter um parto natural, queria minha filha comigo (Helen).

Este depoimento mostra que o parto hospitalar gerou lembranças negativas que prejudicaram o vínculo, sendo que a má vivência impulsionou o casal a buscar formas alternativas de ressignificar a experiência. Diferentemente aconteceu com os casais que já haviam tido um parto domiciliar e que, por ter ocorrido de forma significativa, não deixou outra alternativa com relação ao novo evento:

[...] para nós que já tivemos a experiência de um parto domiciliar, não poderia ser diferente com essa gestação. Seria um retrocesso parir no hospital, quando já se vivenciou um parto domiciliar bem-sucedido (Lúcio).

Lúcio, nesse depoimento, caracteriza o fortalecimento e afirmação de um ideário já construído. Nesse caso, a decisão expande, ilumina e ressalta o que já é comum. Para os casais com filhos mais velhos, a possibilidade de parir em família reafirmava a crença de que o parto deveria ser vivido como um evento do ciclo vital. Sendo assim, as crianças mais velhas seriam envolvidas no processo, "naturalmente". Nas visitas das enfermeiras antes do parto, foi possível observar que, para essas famílias, havia um sentido especial em ter os filhos juntos durante o nascimento de um irmão, já que os mesmos estariam também mudando de status, ou de posição dentro da família:

[...] quero muito que ele participe, tenho conversado com ele sobre o parto, sobre a saída do irmãozinho[...]. Se ele estiver se sentindo bem para estar junto, será ótimo, não quero forçar nada, tem que ser natural (Cecília).

A trajetória de um parto domiciliar é vivenciada com grande empenho e veemência, ultrapassando todos os obstáculos que se interpõem, haja vista, por exemplo, aqueles casais que vêm de outras cidades, deixando seus lares originais, para realizar o sonho de ter um parto fora das amarras institucionais. Essas ações reafirmam que o parto no domicílio, no cenário atual, requer um movimento organizacional que viabilize e suporte essa decisão, mesmo que para isso, seja necessário um enfrentamento da sociedade em geral e seus valores vigentes ${ }^{(5)}$.

\section{A casa e o sagrado}

Com base nos relatos dos informantes, e através da observação dos cotidianos familiares, foi possível perceber que "a casa" é o berço onde se deitam as práticas e as crenças familiares. Desde a maneira de arrumar os espaços internos, até as regras de convivência, implicam na produção de um cenário adequado para o conforto das pessoas que ali residem. Para alguns casais, a possibilidade de parir nesse ambiente traz à tona a tranquilidade de praticar e exercer sua religiosidade, e compartilhar sua visão de mundo, o que talvez não fosse possível realizar em ambiente hospitalar:

[...] queremos usar água do rio Ganges no parto. Não sabemos ainda como. Nosso amigo que veio da Índia trouxe para nós. Aliás, um dos motivos que queremos ter o parto em casa é porque aqui vamos poder praticar as coisas que acreditamos (Ana).

As famílias que se coadunam com a prática do parto domiciliar geralmente associam as maternidades ou instituições hospitalares a ambientes frios, repletos de pessoas estranhas e que realizam os cuidados de maneira rotineira, sem envolvimento afetivo ${ }^{(15)}$. Esse estranhamento faz com que o parto se torne algo não familiar, representando o "mundo de fora". Já a casa, com todos os utensílios, objetos e atmosfera do "mundo doméstico", são tomados como ferramenta de domínio e conhecimento, que possibilitam os participantes a acessarem uma dimensão transcendente, que transforma o parto num evento paradigmático, fundamental para a vivência familiar ${ }^{(4)}$, como podemos perceber no discurso de Orest:

Fomos visitar a maternidade e ficamos impressionados. Eu me senti um estranho lá dentro. Quando ela falou da possibilidade de ter filho em casa, isso me trouxe uma tranquilidade imensa; agora sim eu consigo até imaginar o parto; o nosso parto.

Tais resultados aproximam o pensamento de que a casa reflete aquilo que o casal ou a família acredita, e nela está 
impresso o seu modo de vida, o que favorece imensamente a autonomia pessoal e a espontaneidade emocional, tão fundamentais ao protagonismo do parto. Estudos revelam que a ambiência do local do parto está diretamente relacionada com o bem-estar da mulher e do recém-nascido ${ }^{(1-4,8,10)}$.

Muitas famílias deste estudo demonstraram que cultivam o ambiente do lar como sendo um espaço sagrado onde praticam sua religiosidade:

[...] a pequena casa tem chão de cimento. Na entrada, um espaço para se deixar os sapatos [...]. No quarto do casal, além da cama, há um armário e uma 'arara' com roupas penduradas. Um espaço nobre foi reservado para um altar improvisado em duas caixas de madeira sobrepostas. Nesse altar, criteriosamente arranjados, encontram-se pedras, cristais, colares, penas, incensos, fotos pequenas, estátuas de barro, figuras indianas, vários frascos contendo pós de cores diversas, óleos essenciais, mandalas, velas e muitas outras coisas miúdas... (notas de observação - Graça e Gil).

As maneiras de organizar os espaços internos da casa e as disposições dos objetos variam de acordo com os costumes familiares, porém, a presença de altares, velas e flores reafirmam que existe um estilo comum aos que partilham os valores da “Nova Era"(16-17). São detalhes reveladores de que o imanente está impregnado pelo transcendente. Para essas famílias, o parto domiciliar se coaduna com um sistema alternativo que busca novas práticas relacionadas ao nascimento, pois cultivam especificidades próprias em relação à gestação e ao parto, bem como aos sentidos que devem ser atribuídos a estes eventos, principalmente no que diz respeito às relações que estabelecem com o misticismo e a religiosidade ${ }^{(4)}$, e isso é claramente visível em sua prática cotidiana, afirmando o pensamento de que o ambiente da casa reflete os valores em que acreditam:

[...] nós seguimos um pouco de cada coisa. Hinduísmo, budismo... com essas filosofias a gente faz um caminho de transformação individual (Gil e Graça - intercalando entre as frases).

[...] não temos uma religião vinculada a uma crença específica (Cícero).

\section{B. Preparando a chegada do bebê}

As famílias realizam rituais específicos que formalizam os cuidados com o corpo grávido, com a preparação concreta para o parto e a chegada da nova criança. Teóricos da antropologia registram em suas obras que os rituais preparatórios para o nascimento são realizados desde muito tempo em todas as culturas, mostrando que estes são intensamente revestidos de poder para transformar a vida social das pessoas envolvidas ${ }^{(7,13,15)}$. Esses rituais são dotados de um conjunto de significados que visam reduzir a incerteza, promover apoio emocional para o indivíduo e facilitar a transição de papéis e de status, renovando a ordem social ${ }^{(15)}$.

\section{O preparo do corpo e da mente para dar à luz}

O período pré-natal mostrou-se bastante valorizado pelos adeptos do parto domiciliar, por compreenderem que, durante a gestação, o mundo social em que a mulher está inserida influencia sobremaneira o bem-estar e a saúde fetal. Nesta interpretação, não apenas as emoções da mãe passam vitalidade para o feto, mas também suas práticas. Por isso, essas famílias prezam ter uma boa qualidade de vida durante a gestação ${ }^{(4)}$. Para elas, o preparo do corpo para a vivência do parto pareceu ser um dos pontos-chave. Esse foi um achado frequente entre as mulheres, ao serem questionadas sobre suas atividades cotidianas e o preparo do corpo para dar à luz:

[...] sou ativa, estou o tempo todo me agachando e levantando, arrumando as coisas no quintal, e agora que parei de trabalhar, vou me dedicar mais às caminhadas. Também me alimento super bem, temos uma prática de alimentação natural (Cecília).

Este testemunho demonstra a incorporação de significados de preparação para o parto às atividades cotidianas, com o objetivo específico de preparar o corpo para o "bem-parir"(4). Para aquelas, no entanto, que julgavam não ter uma vida tão regrada antes da gestação, observamos que o fato de estarem grávidas mudou o foco das preocupações, quando então deixaram de lado algumas práticas que julgavam nocivas para o novo status, como por exemplo, a alimentação desregrada, o uso de cigarro, álcool e algumas medicações, e passaram a cuidarem-se mais, vislumbrando as condições que julgavam mais apropriadas para a realização do parto fora do ambiente hospitalar. Para elas, o desejo de vivenciar um parto vaginal e em casa impulsionou uma atitude proativa de mudança comportamental.

Também foi possível identificar que as mulheres buscaram apoio na literatura para a construção de um conhecimento específico acerca da preparação para o parto. O livro "Parto Ativo", de Janet Balaskas, pareceu ser "a bíblia" do parto, presente em praticamente todas as casas visitadas. Além desse, os livros de Michel Odent e Frederick Leboyer, obstetras "de vanguarda", considerados ícones da humanização do parto, também serviram como referência. As "inovações" propostas por essas correntes obstétricas propõem a incorporação de uma ideologia libertária no campo da parturição ${ }^{(4,14)}$. As mulheres procuram nessas obras um alicerce para o preparo do corpo e da mente. Isso fica claro no depoimento de Joana:

[...] li muitos livros de gestação e parto ativos e desde então prático yoga e meditação todos os dias de manhã, aqui na sala mesmo.

No Brasil, a partir das décadas de 60 e 70, houve um crescimento de novas formas de espiritualidade combinadas com práticas terapêuticas não convencionais ou alternativas, usadas principalmente pelas classes médias urbanas ${ }^{(15)}$. A adoção de um comportamento terapêutico ou espiritualizado modificou também outras escolhas, entre elas, a preferência por "medicinas suaves"(16), homeopatia, acupuntura, remédios naturais, e, inclusive, a escola dos filhos, que segue uma linha de instituições alternativas, com pedagogia mais ligada aos 
valores espirituais, ecológicos ou mesmo políticos do país ${ }^{(16)}$. Trazendo para o contexto dessa pesquisa, foi possível perceber que os informantes tinham tendência a realizar ações de cuidado ligadas às práticas consideradas por eles como "naturais", usando, pois, os elementos disponíveis na "natureza".

Contudo, esses casais não recusam totalmente as práticas hegemônicas vigentes, mas se propõem a adotar um estilo de vida baseado em princípios menos segmentaristas, entre eles, o estilo de "vida comunitária", o consumo regulado, o cultivo da espiritualidade, a produção e/ou consumo de alimentos sem agrotóxicos e a alimentação com base na macrobiótica ou vegetarianismo(17). São adeptos de fórmulas "alternativas", estudam sobre o assunto e se autoindicam terapias específicas e particulares, sempre que preveem alterações no processo saúde-doença. Diante dos desconfortos enfrentados pela grávida, por exemplo, aliviam as aflições, utilizando terapêuticas idiossincráticas, o que mostra que assumem as responsabilidades sobre seus corpos, não delegando isso aos profissionais médicos, embora algumas vezes procedam em consonância com os mesmos, mas agindo em processos de co-negociação:

[...] estava com prisão de ventre, fiz uma prática da medicina Ayurveda, com a aplicação de $60 \mathrm{ml}$ de óleo de gergelim, com uma pitada de sal de rocha morno, via retal. No dia seguinte o intestino voltou a funcionar. Repeti a prática por três dias. Também mergulhei um O.B. no óleo de gergelim morno e coloquei intravaginal, por uma noite. Isso é bom para preparar o canal de parto para a passagem do bebê (Ana - nota de observação, na visita da enfermeira).

Essas ações remetem ao conceito de autoatenção, por envolver práticas que buscam prevenir, ou curar alguma situação de saúde, levando em consideração que essas práticas estão relacionadas tanto com as condições técnicas e científicas, como também com as crenças religiosas e modo de vida de quem as pratica ${ }^{(18)}$. Nesta perspectiva também foi possível observar rituais específicos de preparação para o parto, como representado na seguinte fala:

\section{[...] fazer o Temascal* foi maravilhoso para eu me conectar com} a gestação, com o parto e, principalmente, com o lance da superação, de aguentar firme; é difícil, porque no Temascal você pode desistir e sair da tenda, é diferente do parto, no parto não tem jeito de sair dele, a não ser com o bebê no colo, ou quando a mulher está num hospital e se entrega para a intervenção. Mas eu escolhi ficar até o fim, eu vi que estava conseguindo, e isso estava me fazendo bem, saí de lá com a sensação de que no parto eu vou até o fim, naturalmente (Laís).

Contudo, cabe ressaltar que nem todas as mulheres tiveram tempo para realizar preparação física especial para o parto, pois faziam parte de uma parcela da população feminina que se dedica quase que exclusivamente ao trabalho fora de casa, para ajudar no orçamento familiar, mas, ainda assim, estavam dispostas a vivenciar o parto domiciliar, como foi o caso de Bela, que disse:

Eu não tenho tempo pra nada [...] como não passei pela experiência do parto ainda nessa vida, não sei nada, vou deixar meu corpo me levar.

\section{Vislumbrando o momento do parto}

A idealização sobre o parto ocorrer na água apareceu repetidamente, sempre que as mulheres cogitavam o tipo de parto que queriam ter em casa, dispondo de uma dose considerável de confiança naquilo que já leram sobre o tema.

Eu pensei em usar a água no trabalho de parto, sei que reduz muito a sensação de dor, mas ainda não me vejo parindo na água, sou muito terra, tipo pé no chão. Acho que vou acabar parindo de cócoras, eu gosto dessa posição (Odília).

Os homens, companheiros das gestantes, também contribuíram significativamente com a idealização do parto na água, apoiando-as e incentivando-as para a experiência:

O parto da Joana vai ser tranquilo, o menino vai sair pela vagina, mergulhar na água, vamos pegá-lo e colocá-lo no seio para mamar [...] (Júlio).

Esses depoimentos contribuem para mostrar que os companheiros, no parto domiciliar, se colocam não apenas como acompanhantes, mas como sujeitos ativos, envolvidos integralmente no processo de nascerem também como pais, reafirmando a parceria igualitária ${ }^{(8)}$, que se traduz na redução das diferenças de gênero, aproximando os homens do universo feminino.

As famílias, principalmente, as mulheres, se prepararam para que o trabalho de parto transcorresse da melhor maneira possível. Para isso, estudaram com afinco todas as possibilidades e compartilharam com as pessoas que estariam no parto:

[...] vou usar óleo essencial de gengibre. Tem estudos que mostram que quando inalado, diminui o tempo de trabaIho de parto, por isso, se precisar eu uso. Tem outros aromas e florais separados também (Cecília).

A diversidade de recursos terapêuticos reflete que o sistema de cuidado está geralmente dissociado da maioria dos preceitos considerados da alçada específica da biomedicina ${ }^{(18)}$, embora procurem equipes de profissionais de saúde com especialidade na atenção obstétrica.

\section{Planejando a recepção do bebê}

Sendo o parto domiciliar um evento notadamente marcado

* Temascal é uma terapia ritualística iniciada pelas culturas pré-colombianas e significa "tenda do suor". Trata-se de uma estrutura fechada em formato de iglu, onde são colocadas pedras quentes, ao redor das quais permanecem as pessoas que irão vivenciar a experiência. O facilitador fecha a tenda e molha as pedras com água, usando ramalhete de ervas aromáticas. A finalidade é produzir vapor de calor intenso, que representa o útero ${ }^{(19)}$. 
pela presença de práticas terapêuticas não convencionais ou "alternativas"(16), identificou-se que também a relação com o novo ser humano que está por chegar, associa-se a essa representação:

[...] estou lendo um livro especial, que chama 'Nutrindo a alma do seu bebê'. Nele tem mentalizações que pratico todos os dias de manhã. O livro é da linha do novo espiritismo. Com isso, busco transmutar, antes dela [filha] nascer, todo o carma negativo que ela possa vir a ter (Flávia).

Os cuidados preparatórios para a chegada da criança são embebidos na simbologia de arrumar o "ninho" para recebê-la:

[...] não reparem a bagunça, estamos em obra, aumentando o nosso quarto para caber o berço. Estamos finalizando o ninho para a chegada do bebê (Cecília).

A fala de Cecília ratifica que a lógica do parto domiciliar é diferente, pois a família não vai até o hospital para "buscar" o novo integrante, e sim, arruma o ambiente para receber o filho que vai "chegar". Os detalhes para essa recepção foram construídos durante o curso da gestação e se intensificaram nos dias que antecederam o parto. A expectativa e o planejamento para a chegada do neófito, em algumas famílias, associavam-se à data de sua chegada, com os ciclos da natureza, como revela a fala de Graça:

Acho que pode nascer no dia 23, pois é lua cheia, e nessa época o filho será do signo de Libra, igual ao meu.

Essa perspectiva é representativa que os indivíduos não são independentes da natureza, e sim, um continuum do universo que, por sua vez, também está submetido a ritmos que afetam a vida humana. Diante disso, associam as cerimônias de passagens humanas às que se relacionam com as passagens cósmicas, como as fases da lua, por exemplo, que são reconhecidas por "contar o tempo na terra"(7).

Através desses resultados, percebe-se que os casais movimentam uma série de rituais de cuidado para esse momento de "separação"(7), onde a mulher gestante se tornará mãe, o homem será pai e o que está chegando se tornará filho. A preparação específica para o recebimento do forasteiro direciona ações previamente planejadas, com a finalidade de respeitar o momento de transição da vida intraútero, para a vida extrauterina:

Não queremos cortar o cordão umbilical logo, queremos esperar pelo menos duas horas. Li que existe um tempo de troca energética entre a placenta e o bebê, via cordão, por isso, queremos deixá-lo ligado à placenta mais tempo [...] também não queremos colocar roupas logo que ele nascer; queremos ficar pele a pele com ele o tempo que for preciso. Queremos que ele faça uma transição suave (Joana).

A prática "alternativa" comumente associada ao parto domiciliar está relacionada à ideia de um ruptura com certos padrões e convenções sociais, além de uma reorganização de práticas, concomitante à construção de um modo de vida considerado mais saudável ${ }^{(4)}$. Todavia, esse comportamento geralmente tem um fundamento lógico, embasado em estudos que comprovam os benefícios de adotar esse estilo de vida, incluindo o planejamento dos cuidados com o bebê que nascerá:

Não vamos dar banho nela quando nascer. Existem estudos que recomendam isso. Os bebês nascem com uma camada protetora na pele e é muito importante que se preserve essa camada nas primeiras semanas de vida, pois previne irritações na pele do bebê (Eduardo).

Os ritos de cuidado com o recém-nascido, na compreensão dessas famílias, são planejados para serem praticados com o objetivo de prevenir problemas de saúde e os malefícios a que está sujeito, por sua condição especial de fragilidade e de ser "novo" como ser humano, conforme sugerem outros estudos na área ${ }^{(15)}$.

\section{CONSIDERAÇÕES FINAIS}

A construção do ideário do parto em casa é permeada por uma rede de símbolos e significados que liga a gestação a um evento esperado da fase reprodutiva e que faz parte de um ciclo da vida que esses casais e famílias consideram como "natural", assumindo uma postura diferenciada do que postula o atual modelo de atenção ao parto e nascimento oferecido pelas instituições hospitalares.

A priori, o espaço da casa está intimamente relacionado a um ambiente que é considerado "extra-ordinário", onde as famílias praticam sua religiosidade e cultivam relação com aquilo que acreditam religá-las ao universo, particularmente na vivência de um fenômeno que traduz vida e renovação, como é o de gestar uma nova existência. Os rituais de preparação do corpo da gestante para vivência do parto estão sempre relacionados às práticas terapêuticas que seguem, segundo suas percepções, uma linha "alternativa" de autocuidado. No que se refere aos preparativos para a chegada do bebê, constata-se que as famílias desenvolvem ações que simbolizam arrumar o "ninho" para receber o novo integrante da unidade familiar. $\mathrm{O}$ planejamento dessa recepção se materializa em atividades e decisões, em prol de uma recepção respeitosa e aconchegante, que auxilie o bebê a realizar a "passagem" de forma mais suave, e a enfrentar a condição de fragilidade a ela inerente.

Os rituais de cuidado realizados durante a fase de preparação para a vivência do parto no domicílio servem como baliza para compreender a cultura familiar, uma vez que essas práticas evocam o modo de viver dos casais grávidos e suas redes sociais, quase sempre, em movimentos de resistência ao modelo de atenção ao parto em nível hospitalar. O entendimento dos rituais de cuidado contribui para que as enfermeiras obstétricas reconheçam os símbolos e significados impressos nessas performances, respeitem esses rituais enquanto práticas culturais que auxiliam as famílias a marcarem os novos papéis sociais e a buscarem negociações respeitosas para a prática profissional nos domicílios, durante o transcorrer do parto. 


\section{REFERÊNCIAS}

1. Koettker JG, Brüggemann OM, Dufloth RM, Knobel R, Monticelli M. Resultado de partos domiciliares atendidos por enfermeiras de 2005 a 2009 em Florianópolis, SC. Rev Saúde Pública. 2012;46(4):747-50.

2. Colacioppo PM, Koiffman MD, Riesco MLG, Schneck CA, Osava RH. Parto domiciliar planejado: resultados maternos e neonatais. Referencia. 2010;III(2):81-90.

3. Medeiros RMK, Santos IMM, Silva LR. A escolha pelo parto domiciliar: história de vida de mulheres que vivenciaram esta experiência. Esc Anna Nery Rev Enferm. 2008;12(4):765-72.

4. Souza HR. A arte de nascer em casa: um olhar antropológico sobre ética, a estética e a sociabilidade do parto domiciliar contemporâneo. Florianópolis. Dissertação [Mestrado em Antropologia Social] - Universidade Federal de Santa Catarina; 2005.

5. Martins CA, Almeida NAM, de Mattos DV. Parto domiciliar planejado: assistido por enfermeiro obstetra. Enferm Glob. [acesso em 05 ago 2012]. Disponível em: http:// revistas.um.es/eglobal/article/viewFile/136391/136381

6. Monticelli M, Elsen I. A cultura como obstáculo: percepções da enfermagem no cuidado às famílias em alojamento conjunto. Texto \& Contexto Enferm. 2006;15(1):26-34.

7. Gennep AV. Os ritos de passagem. Rio de Janeiro: Vozes; 2011.

8. Salem T. O casal grávido: disposições e dilemas da parceria igualitária. Rio de Janeiro: Fundação Getúlio Vargas; 2007.

9. Leininger MM, Mc Farland MR. Culture care diversity and universality: a worldwide nursing theory. New York (NY): McGraw-Hill; 2006.

10. Davis-Floyd R. The technocratic, humanistic, and holistic paradigms of childbirth. Int J Gynecol Obstet. 2001;75(Suppl1):S5-S23.

11. Fontanella BJB, Rica J, Turato ER. Amostragem por saturação em pesquisas qualitativas em saúde: contribuições teóricas. Cad Saúde Pública. 2008;24(1):17-27.

12. Trentini $M$, Paim LMD. Pesquisa em enfermagem: uma modalidade convergente-assistencial. Florianópolis: UFSC; 2004.

13. Geertz C. O saber local: novos ensaios em antropologia interpretativa. Petrópolis: Vozes; 1997.

14. Tornquist CS. Parto e poder: o movimento pela humanização do parto no Brasil. Florianópolis. Tese [Doutorado em Antropologia Social] - Universidade Federal de Santa Catarina; 2004.

15. Monticelli M. Rituais de vida e de cuidado com o nascimento. In: Elsen I, Marcon SS, Silva MRS, organizadores. O viver em família e sua interface com a saúde e a doença. Maringá: Eduem; 2002. p.141-54.

16. Maluf SW. Mitos coletivos, narrativas pessoais: cura ritual, trabalho terapêutico e emergência do sujeito nas culturas da "Nova Era". Mana. 2005;(11)2:499-528.

17. Magnani JGC. O Brasil da Nova Era. Rio de Janeiro: Zahar; 2000.

18. Oliveira DLLC. A enfermagem e suas apostas no autocuidado: investimentos emancipatórios ou práticas de sujeição? Rev Bras Enferm. 2011;64(1):185-88.

19. Contreras ATR. Visiones sobre el temazcal mesoamericano: un elemento cultural polifacético. Ciência Ergo Sum. [periódico de Internet]. 2001 [acesso em 30 set 2011];8(2):[cerca de 10p]. Disponível em: http://redalyc. uaemex.mx/pdf/104/10402103.pdf 